\title{
Kajian Konsep Arsitektur Ekologi Pada Kawasan Resort Studi Kasus: Pulau Ayer resort and Cottages
}

\section{Study of Ecological Architecture Concepts in Resort Areas Case Study: Ayer Island resort and Cottages}

\author{
${ }^{*}$ Risnan Nazarudin', Anisa \\ 1,2 Program Studi Arsitektur Fakultas Teknik \\ Universitas Muhammadiyah Jakarta,, Indonesia \\ Diterima: Februari 2020; Disetujui: April 2020; Dipublikasi: 30 April 2020 \\ *Corresponding author: E-mail : anisa@ftumi.ac.id
}

\begin{abstract}
Abstrak
Kawasan Resort merupakan tempat rekreasi yang dituju oleh masyarakat kota. Pesatnya perkembangan kota mempunyai dampak yang besar pada daerah di sekitar kota. Daerah sekitar kota menjadi arah pembangunan yang kadangkala tidak terkontrol sehingga menyebabkan kerusakan lingkungan yang ditandai dengan penurunan kualitas udara, air, tanah, punahnya flora dan fauna liar dan rusaknya ekosistem. Berdasarkan latar belakang tersebut maka perlu penerapan arsitektur ekologi pada pembangunan fasilitas pendukung kota, antara lain resort. Penelitian ini bertujuan untuk memahami penerapan prinsip prinsip arsitektur ekologi pada kawasan resort dan mengidentifikasi material apa saja yang mendukung arsitektur ekologi pada kawasan resort. Metode yang digunakan deskriptif kualitatif, yang menganalisis menggunakan prinsip arsitektir ekologi. Diharapkan dengan adanya penerapan arsitektur ekologi pada kawasan resort ini bisa membuat lingkungan terjaga ekosistemnya dan meminimalisirkan pengaruh buruk pada lingkungan yang di timbulkan karena desain arsitektur yang tidak tepat. Hasil dari penelitian ini adalah, prinsip ekologi bisa diterapkan dalam kawasan resort antara lain mengatur massa bangunan untuk menciptakan ruang terbuka hijau aktif, memanfaatkan kontur dan keistimewaan fisik alamiah, mendesain bangunan supaya hemat energy dengan bukaan yang cukup dan arah hadap yang tepat, dan menggunakan material local.
\end{abstract}

Kata Kunci : Arsitektur ekologi, Kawasan Resort, Lingkungan.

\begin{abstract}
Kawasan Resort is a recreational destination for the city community. The rapid development of the city has a large impact on the area around the city. The area around the city is the direction of development that is sometimes uncontrolled, causing environmental damage which is characterized by a decrease in the quality of air, water, soil, extinction of wild flora and fauna and damage to ecosystems. Based on this background it is necessary to apply ecological architecture to the construction of supporting facilities for the city, including resorts. This study aims to understand the application of the principles of ecological architecture in the resort area and identify any material that supports the ecological architecture in the resort area. The method used is descriptive qualitative, which analyzes using the principle of ecological architecture. It is expected that with the application of ecological architecture in this resort area, the environment will be able to maintain the ecosystem and minimize adverse effects on the environment caused by inappropriate architectural designs. The results of this study are, the ecological principle can be
\end{abstract}


Risnan Nazaruddin, Annisa , Kajian Konsep Arsitektur Ekologi pada Kawasan Resort

applied in resort areas including regulating building masses to create active green open spaces, utilizing natural physical contours and features, designing buildings to save energy with adequate openings and the right direction, and using materials Workshop Case: Ayer Island Resort and Cottages

Keywords: Ecological architecture, Resort District, Environment.

How to Cite : N. Risnan, Annisa, (2020), Kajian Konsep Arsitektur Ekologi pada Kawasan Resort Studi Kasus Pulau Ayer Resort dan Cottage, J ournal of Architecture and Urbanism Research, 3 (2): Hal 129-138 


\section{PENDAHULUAN}

Pada masa sekarang, dengan banyaknya kebutuhan dan keinginan manusia menyebabkan kesadaran terhadap lingkungan mulai menurun, lingkungan hidup yang rusak secara langsung telah mengancam kehidupan manusia. Rusaknya lingkungan hidup pun menyebabkan resiko bencana alam, di tandai dengan penurunan kualitas udara, air, tanah, punahnya flora dan fauna liar dan rusaknya ekosistem. Meningkatnya Populasi manusia yang diiringi kemajuan teknologi yang pesat, maka terjadilah eksploitasi pada sumber daya alam sehingga menimbulkan dampak buruk pada alam dan lingkungan hidup.

Arsitektur menjadi salah satu bidang ilmu yang dipandang memiliki andil bagi kerusakan lingkungan yang terjadi saat ini. (Titisari E, Joko T, \& Noviani, 2012). Salah satu konsep yang berkembang dan menjadi rujukan dalam ilmu arsitketur adalah arsitektur ekologis. Konsep ini mengajarkan tentang hubungan timbal balik antara makhluk hidup dan lingkungannya. (Frick \& Bambang, 2007). Menurut (Ryn \& Cowan, 2006) Suatu kawasan dapat dikatakan ekologis atau tidak setelah melalui serangkaian penilaian ataupun analisa yang didasarkan atas prinsip-prinsip desain ekologis yang diterapkan pada bangunan tersebut (Utami, Sri, \& Ummul, 2017), (Adi, 2017)

Penelitian ini mengambil studi kasus bangunan Resort untuk melihat penerapan prinsip arsitektur ekologi dalam desainnya. Diharapkannya dengan adanya perencanaan dan perancangan kawasan resort dengan pendekatan arsitektur ekologi ini bisa mengatasi dan mengurangi pengaruh buruk pada lingkungan yang mungkin ditimbulkan karena desain arsitektur yang tidak tepat.
Berdasarkan latar belakang yang dikemukakan, maka rumusan masalah dalam penelitian ini adalah : (1) Bagaimana penerapan arsitektur ekologi pada kawasan resort?; (2) Material apa saja yang mendukung arsitektur ekologi pada kawasan resort?. Tujuan dari penelitian ini adalah untuk mengidentifikasi dan mendeskripsikan penerapan prinsip arsitektur ekologi, dan material yang dapat mendukung arsitektur ekologi pada kawasan resort.

Ekologi sesuatu hal hal yang saling mempengaruhi, istilah ekologi pertama di perkenalkan oleh Ernst Haeckel, ahli ilmu hewan pada tahun 1869 sebagai ilmu interaksi antara segala jenis mahkluk hidup dan lingkunganya. Dalam Bahasa Yunani oikos adalah rumah tangga atau cara bertempat tinggal, dan logos bersifat ilmu atau ilmiah. Jadi ekologi bearti ilmu tentang rumah atau tempat tinggal mahluk hidup. Ekologi dapat didefinisikan sebagai ilmu yang mempelajari hubungan timbal balik natra mahluk hidup dan lingkunganya (Frick \& Bambang, 2007). (Hakim \& Budi, 2017).

Arsitektur ekologi merupakan suatu pendekatan perencanaan bangunan yang berusaha untuk Mengupayakan terpeliharanya sumber daya alam, membantu mengurangi dampak yang lebih parah dari pemanasan global, melalui pemahaman prilaku alam. Mengelola tanah, air dan udara untuk menjamin keberlangsungan siklus-siklus ekosistim didalamnya, melalui sikap transenden terhadap alam tanpa melupakan bahwa manusia adalan imanen dengan alam. Tujuan utama dari arsitektur ekologi adalah menciptakan eco desain, arsitektur ramah lingkungan. Konsep ekologis merupakan konsep penataan lingkungan dengan memanfaatkan potensi atau sumberdaya 
alam dan penggunaan teknologi berdasarkan manajemen etis yang ramah lingkungan. (Sidik \& Daniel, 2016).

"Arsitektur Ekologi" yaitu, menciptakan sebuah bangunan yang berwawasan lingkungan, dengan cara memanfaatkan sember daya energi alami dan meminimalisasi dampak buruk yang diakibatkan oleh berdirinya sebuah bangunan. (Mahardika \& Widji, 2013). Menurut Heinz Frick dalam (Muslim, Ashadi, \& Anggana, 2018) Arsitektur ekologi adalah keselarasan antara bangunan dengan alam sekitarnya, atau biasa disebut arsitektur yang berwawasan lingkungan.

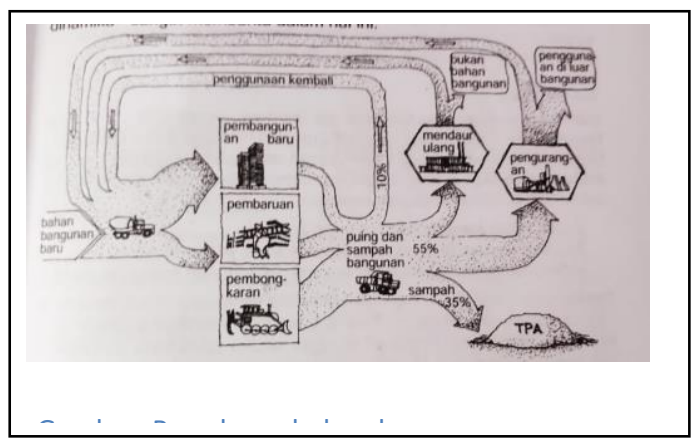

Gambar 1. Prinsip Desain

Pada cakupan yang lebih luas, Cowan dan Ryn dalam (Adi, 2017) mengemukakan prinsip-prinsip desain yang ekologis sebagai berikut:

Solution Grows from Place: solusi atas seluruh permasalahan desain harus berasal dari lingkungan di mana arsitektur itu akan dibangun. Prinsipnya adalah memanfaatkan potensi dan sumber daya lingkungan untuk mengatasi setiap persoalan desain.

Ecological Acounting Informs Design: perhitungan-perhitungan ekologis merupakan upaya untuk memperkecil dampak negatif terhadap lingkungan.

Design with Nature: arsitektur merupakan bagian dari alam. Untuk itu setiap desain arsitektur harus mampu menjaga kelangsungan hidup setiap unsur ekosistem yang ada di dalamnya sehingga tidak merusak lingkungan.

Everyone is a Designer: melibatkan setiap pihak yang terlibat dalam proses desain. Tidak ada yang bertindak sebagai user atau participant saja atau designer/ arsitek saja. Setiap orang adalah participant-designer.

Make Nature Visible: proses-proses alamiah merupakan proses yang siklis. Arsitektur sebaiknya juga mampu untuk melakukan proses tersebut sehingga limbah yang dihasilkan dapat ditekan seminimal mungkin.

Menurut Hui dalam (Titisari E, Joko T, \& Noviani, 2012), melengkapi prinsip tersebut di atas dengan mengemukakan prinsip understanding people yang intinya pada upaya memahami konteks budaya, agama, ras, perilaku, dan kebiasaan (adat) masyarakat yang akan diwadahi oleh arsitektur. Prinsip-prinsip Hui yang lain adalah: Understanding Place, Connecting with Nature, Understanding Natural Processes, Understanding Environmental Impact, dan Embracing Co-creative Design Processes.

Berdasarkan pendapat para ahli-ahli milik Frick, Widigdo dan Metallinaou dalam (Utami, Sri, \& Ummul, 2017) tentang Arsitektur Ekologis tersebut, pada intinya pendekatan arsitektur ekologis pada arsitektur mengarah ke :

1. Memelihara sumber daya alam. memelihara sumber daya alam yang akan dicapai dengan kriteria menghadirkan banyak ruang terbuka untuk mempertahankan keberadaan pohon.

2. Mengelola tanah, air dan udara. Tujuannya agar bangunan dapat memenuhi kebutuhannya sendiri 
dengan cara memaksalmalkan potensi alam yang telah dikelola. Prinsip ini berusaha agar air dapat terserap ke tanah, adanya pemisahan sampah organik dan anorganik untuk memelihara tanah, dan adanya ruang terbuka sebagai tempat hidup pohon yang dapat menyediakan suplai udara bersih.

3. Menggunakan sistem-sistem bangunan yang hemat energy. Menggunakan sistem bangunan hemat energi yang dalam hal ini berusaha memaksimalkan pemanfaatan sumber daya dari alam terutama cahaya matahari dan angin.

4. Menggunakan material lokal. Prinsip menggunakan material lokal dengan cara menggunakan material yang mudah didapat dari sekitar tapak yang aman dan sehat bagi kesehatan dan mengekspos penggunaan material lokal pada beberapa bagian bangunan.

5. Meminimalkan dampak negative pada alam. Prinsip meminimalkan dampak negatif pada alam yang berusaha untuk mengurangi pencemaran terhadap udara, air, tanah.

6. Meningkatkan penyerapan gas buang. Gas buang dapat diserap dengan adanya komponen alami yaitu pohon. Tidak hanya menyerap, pohon juga dapat menghasilkan oksigen untuk menghasilkan kualitas udara yang lebih baik.

7. Menggunakan teknologi yang mempertimbangkan nilai-nilai ekologi. Tujuan dari penggunaan teknologi tersebut misalnya untuk meminimalkan dampak negatif pada alam dan untuk menghemat energi. Prinsip ini berusaha untuk menggunakan teknologi untuk megolah limbah dari kegiatan.

Komponen Arsitektur Ekologis yaitu :
1. Konfigurasi bentuk bangunan. Adalah titik sentuh antara massa bangunan dan ruang. Bentuk adalah sebuah istilah inklusif yang memiliki berberapa makna. Ia bisa merujuk pada sebuah penambilan eksternal yang dapat di kenali. (Ching, 2008)

2. Orientasi bangunan. Menurut Wijaya. Dalam (Tyas, Fairuz, Annisa, \& Suci, 2015). Sinar matahari akan memanaskan seluruh bidang bangunan yang menghadap ke arahnya. Arah timur sebagai arah terbit matahari memberikan efek panas yang tidak menyenangkan antara jam 09.00 11.00. Sedangkan arah barat sebagai arah terbenamnya matahari memancarkan panasnya secara maksimal pada jam 13.00 - 15.00 . Matahari memberikan radiasi yang berpengaruh terhadap bangunan. Matahari juga dapat menimbulkan gangguan dari panas dan silau cahayanya.

3. Fasad dan Bukaan. Menurut (majalah idea edisi 63/VI/2009). Dalam (Tyas, Fairuz, Annisa, \& Suci, 2015). Fasad bangunan yang baik agar mendapat pencahayaan yang cukup adalah menghadap utara atau selatan, bukaan yang ada pada fasad pun menghadap utara atau selatan dan tidak terpapar sinar matahari terlalu banyak.

4. Sumber Energi. Sumber energi adalah segala sesuatu di sekitar kita yang mampu menghasilkan energi. Sumber energi tidak terbaharui (nonrenewable) didefinisikan sebagai sumber energi yang tidak dapat diisi atau dibuat kembali oleh alam dalam waktu yang singkat. Energi yang dikonsumsi. Energi yang di konsumsi adalah energi yang kita ginakan dalam beraktivitas sehari sehari. 
5. Kontrol Lingkungan. Kontrol lingkungan adalah bagaimana kita mengelola lingkungan dari kerusakan yang di sebabkan oleh manusia. Bisa di perhatikan dalam polusi udara, sampah dan limbah.

6. Sumber Material. Adalah pemakaian dari produk lokal dimana lebih efisien dalam mendangkan

7. material-materialnya.

8. Hasil Penggunaan Material. Dalam penggunan material yaitu dengan material yang mudah didapatkan dari lingkungan sekitar dan dampak penggunaannya yang tidak berbahaya bagi lingkungan.

9. Tapak.Tapak adalah sebidang tanah dengan ukuran-ukuran yang jelas. Bentuk tapak sanggat berpengaruh dalam merancangan sebuah bangunan agar berdirinya bangunan tidak merusak lingkungan di dalam tapak amupun di luar tapak.

Unsur Pokok Arsitektur Ekologi, menurut (Frick \& Bambang, 2007) dalam (Muslim, Ashadi, \& Anggana, 2018) dan (Pratama, Maya, \& Samsudi, 2018) ekologi arsitektur terdiri dari 4 unsur pokok yaitu udara, api, air dan bumi. Keempat unsur tersebut memberikan unsur timbal balik antara bangunan dengan lingkungan.

\section{METODE PENELITIAN}

Penelitian ini menggunakan metode deskriptif kualitatif dengan mengambil data dan analisis secara deduktif. Metode deskriptif digunakan untuk menganalisis dan menarik kesimpulan berdasarkan hasil analisis tentang penerapan prinsip arsitektur ekologi pada resort yang diteliti. Data dalam penelitian ini berupa data kualitatif, data primer didapatkan dari observasi lapangan secara langsung yang dilengkapi dengan wawancara. Studi kasus yang diteliti adalah Pulau Ayer dan Cottages, yang terletak di Kepulauan Seribu, wilayah DKI Jakarta.

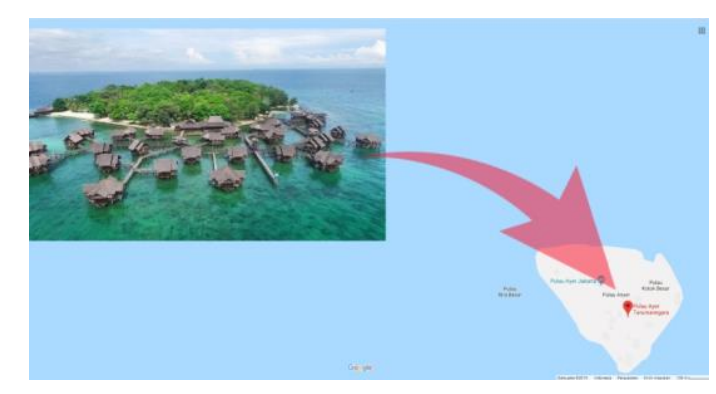

Gambar 2 Pulau Ayer Resort \& Cottages

Metode pengumpulan data pada penelitian ini adalah dengan mencari data fisik dan non fisik dalam mencari data fisik yaitu dengan memilih teori arsitektur ekologi yang sesuai. Teori yang sesuai adalah teori menurut para ahli-ahli milik Frick (2007), Widigdo (2008) dan Metallinaou (2006) tentang arsitektur ekologi. Pada intinya pendekatan arsitektur ekologi pada arsitektur mengarah ke (a) Memelihara sumber daya alam, (b) Mengelola tanah, air dan udara, (c) Menggunakan sistem-sistem bangunan yang hemat energi, (d) Menggunakan material lokal, (e) Meminimalkan dampak negatif pada alam, (f) Meningkatkan penyerapan gas buang (g) Menggunakan teknologi yang mempertimbangkan nilainilai ekologi.

\section{HASIL DAN PEMBAHASAN}

Prinsip 1: Memelihara Sumber daya alam Pada Studi Kasus yang diteliti, susunan bangunan dalam tapak terdiri dari beberapa massa yang tidak saling menempel antara bangunan satu dan lainya sehingga lebih banyak menghasilkan ruang terbuka hijau untuk tanaman dan resapan air. dan di dukung dengan konfigurasi 
bentuk bangunan tropis sehingga lebih memaksimalkan sumber daya alam seperti udara, dan cahaya sehingga menghemat dalam pemakaian listrik dalam penggunaan AC dan lampu. Penyusunan masa bangunan bisa di lihat pada gambar di bawah ini

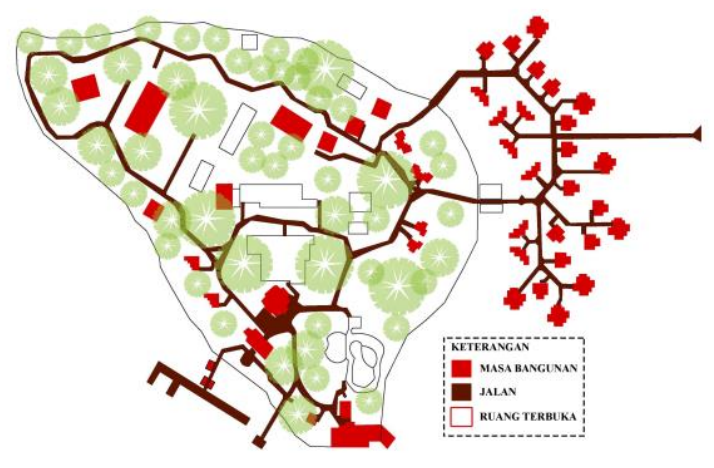

Gambar 3 Site plan pulau ayer \& cottages

Prinsip 2: Mengelola tanah, air dan udara

Dalam mengelola tanah, air dan udara pada kawasan resort ini yaitu dengan menyediakan ruang terbuka hijau yang besar sehingga memberikan ruang untuk pohon agar tumbuh lebih baik sehingga menghasilkan suplai udara yang banyak dan bersih, untuk memaksimalkan tumbuhnya pohon pada jalan menggunakan perkerasan yang masih bisa meresap air ke dalam tanah seperti halnya mengunakan material paving blok di antara penyusunan paving blok masih terdapat jarak sehingga air bisa di kontrol masuk ke dalam tanah. Dalam menjaga tanah di setiap beberapa meter terdapat tempat sampah dan tempat putung rokok sehingga tanah tidak terkontaminasi oleh sampah yang merusak kesuburan tanah.

Dari penelitian bisa di simpulkan bahwa dalam mengelola tanah, air dan udara yaitu dengan melakukan pembangunan dan pengelolaan pada kawasan ini dengan baik. Seperti dalam mengelola tanah dalam pembangunan mengikuti kontur sehingga tidak ada pengurukan dan pembuangan tanah dari lokasi site, dalam menjaga kualitas tanah dengan menjaga tanah terkontaminasi oleh sampah, dalam mengelola air dengan di sediakan ruang terbuka tanpa pengerasan sehingga air dapat meresap kedalam tanah dan air di dalam site tetap stabil, dalam mengelola udara masih tetap di bueri ruang terbuka agar pohon dan tanaman tumbuh lebih baik sehingga bisa menghasilkanudara yang segar.

Prinsip 3: Menggunakan sistem bangunan yang hemat energi

Dalam kawasan resort ini dalam menggunakan sistem bangunan yang hemat energi bisa di lihat dari fasad dan bukaan yang berdiri pada kawasan ini karena sanggat berpengaruh dalam penggunaan energi, seperti penggunaan pendingin ruangan dan lampu. Bisa di lihat pada gambar di bawah ini bentuk fasad dan bukaan yang terdapat di kawasan ini.
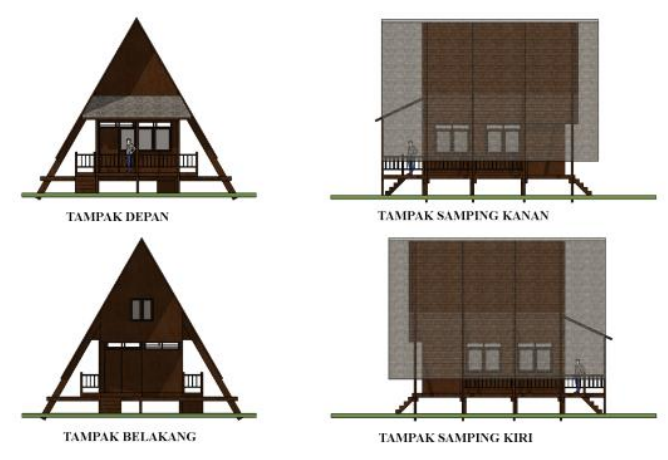

Gambar 4 Bentuk fasad dan bukaan pulau ayer resort \& cottages

Dari studi kasus yang ada bisa di simpulkan bahwa dalam menggunakan sistem-sistem hemat energi yaitu dengan di tekankan pada bentuk fasad dan bukaan, bentuk fasad di sesuai kan dengan iklim 
yang ada dengan kemiringan atap yang cocok pada iklim tropis sehingga dalam menghalau air hujan lebih baik, dalam bukaan juga sangat penting karena berpengaruh dalam penggunaan pendingin ruangan dan lampu.

Prinsip 4: Menggunakan material lokal

Dalam penggunaan material lokal material yang di gunakan dalam bangunan ini yaitu kayu ulin yang di datangkan dari Kalimantan dalam perbaikan sekarang material yang di gunakan adalah kayu dari pohon yang tumbang di kawasan resort ini. Penerapan material kayu hampir semua komponen pada cottages menggunakan material kayu dari struktur dinding dan lantai bisa di lihat pada gambar di bawah ini

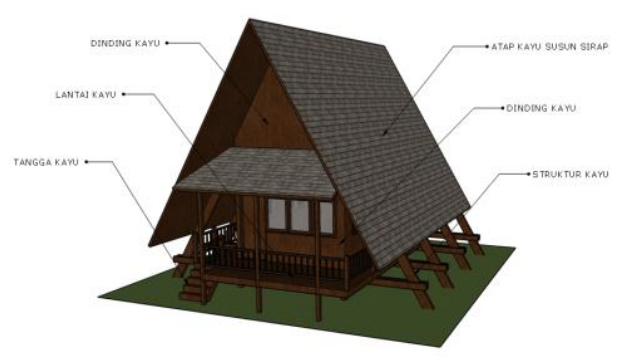

Gambar 5. Penggunaan material lokal pulau ayer resort \& cottages

Prinsip 5: Meminimalkan dampak negatif pada alam

Dalam mengurangi dampak negatif pada kawasan resort ini dengan melakukan pengolahan limbah sampah dan limbah manusia dalam limbah sampah di bagi menjadi 3 yang pertama limbah sampah organik yang berasal dari daun daun pohon di kawasan ini cara menghancurkanya dengan di bakar pada tempat pembuangan sampah yang sudah di sediakan dan ada yang di olah menjadi kompos.

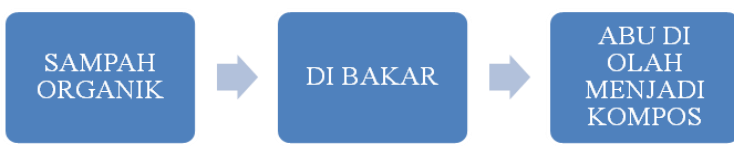

Bagan 1. Bagan Pengolahan sampah
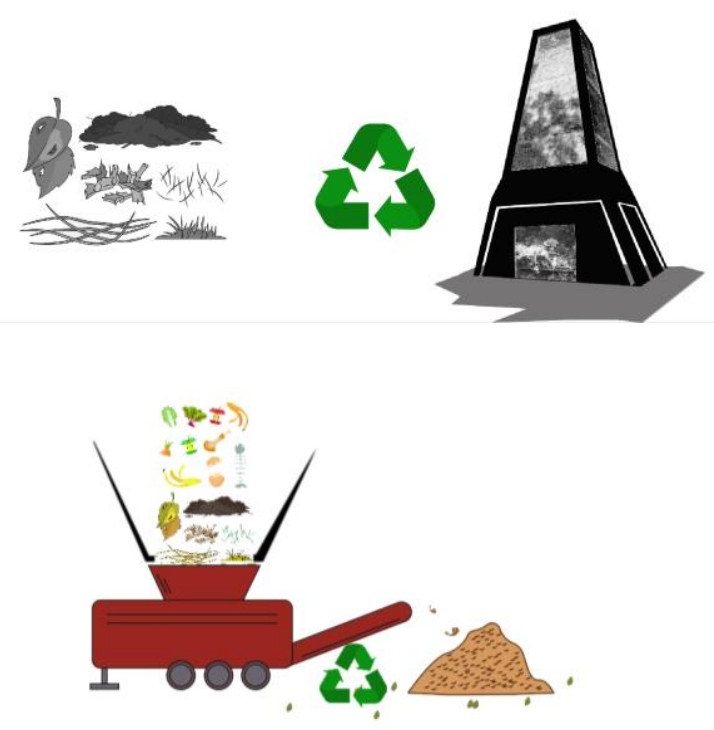

Gambar 6. Pengolahan sampah organik pulau ayer resort \& cottages

Sampah plastik dan botol yaitu di kumpulkan ketika sudah banyak di angkut oleh pengepul dari Jakarta yang datang ke kawasan resort ini

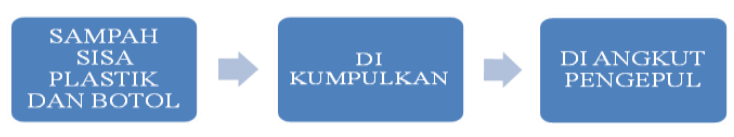

Bagan 2. Bagan Sampah Plastik

Sampah sisa makanan dan tulang belulang ikan cara mengolahanya dengan di komsumsi oleh biawak yang hidup di kawsan resort ini

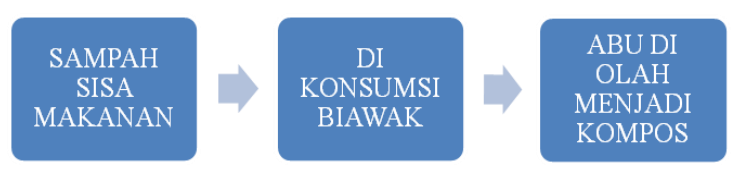

Bagan 3. Bagan Sampah sisa makanan 

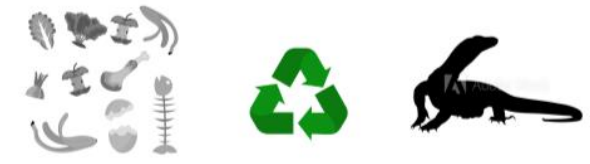

Gambar 7 Pengolahan sampah sisa makanan pulau ayer resort \& conttages

Dalam limbah manusia yaitu tinja di kawasan ini di buatkan septictank untuk pengolahanya agar tidak mencemari lingkungan pada kawasan resort ini

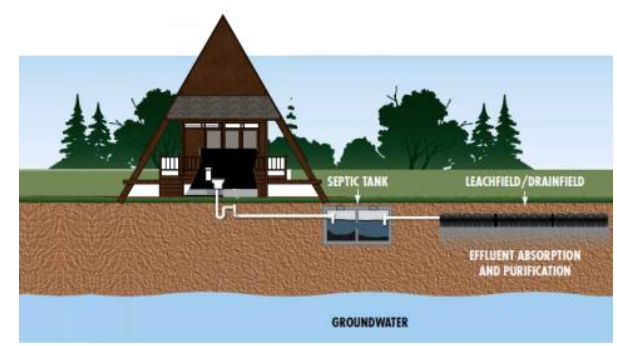

Gambar 8 Pengolahan limbah tinja pulau ayer resort \& cottages

Dari studi kasus yang ada bisa di simpulkan bahwa dalam meminimalkan dampak negatif pada alam dengan di lakukan pengolahan limbah sampah organic maupun anorganik dengan cara di bakar untuk jadi bahan kompos atau di kumpulkan untuk di angkut ke tempatnya, dan juga bisa dilakukan dengan mendirikan bangunan tanpa merusak lingkungan yang sudah ada yaitu dengan sistem modular yang dimana bangunan di bikin di pabrik dan di lokasi tinggal di set.

Prinsip 6: Meningkatkan penyerapan gas buang

Dalam menyerap gas buang dalam kawasan ketiga kawasan ini terdapat banyak pohon pohon besar dan rindang sehingga gas buang yang tidak baik bisa di serap oleh pohon-pohon ini dan di hasilkan gas baru atau oksigen yang segar sehingga kawasan ini terasa sejuk. Dari studi kasus yang ada bisa di simpulkan bahwa dalam dalam penyerapan gas buang dalam semua studi kasus melakukan dengan tumbuhnya pohon-pohon agar pohon tersebut bisa mengolah udara yang tidak baik menjadi udara baik atau segar.

Prinsip 7: Menggunakan teknologi yang mempertimbangkan nilai nilai ekologi

Dalam menggunakan yang mempertimbangkan nilai nilai ekologi pada kawasan resort ini adalah diantara pengunaan lampu led, pendingin ruangan yang eco yang bisa menghemat daya listrik sehingga pemakaian genset pada kawasan ini lebih kecil, sehingga bisa mengurangi gas buang yang di hasilkan oleh genset tersebut. Dalam ruang yang di susun yaitu di buat sesui dengan fungsi nya agar ruang yang di dapat lebih efektif dan bisa mengoptimalkan fungsi bangunan secara maksimal.

Dari studi kasus yang ada bisa di simpulkan bahwa dalam Menggunakan teknologi yang mempertimbangkan nilai nilai ekologi dari elektronik itu sendiri bisa menggunakan pendingin ruangan yang sudah berstandar eco, dan penerangan menggunakan lampu led karena lampu jenis ini lebih hemat daya listriknya, dalam bangunan bisa dengan menggunakan bahan baku kayu yang sesui dengan lokasi sehingga bangunan yang berdiri tetap menyatu dengan alam sehingga tidak merusak ekosistem yang ada.

\section{SIMPULAN}

Berdasarkan analisis yang telah dilakukan, dapat diambil kesimpulan sebagai berikut: Pengaturan massa bangunan yang tepat, dengan menciptakan ruang terbuka hijau yang banyak merupakan penerapan prinsip memelihara sumber daya alam pada kawasan resort. 
Dalam mengelola tanah, air dan udara yaitu dengan melakukan pembangunan dan pengelolaan pada kawasan ini dengan baik. Seperti dalam mengelola tanah dalam pembangunan mengikuti kontur, menjaga kualitas tanah dengan menjaga tanah terkontaminasi oleh sampah, mengelola air dengan menyediakan ruang terbuka tanpa pengerasan sehingga air dapat meresap kedalam tanah. Menggunakan sistemsistem hemat energi yaitu di tekankan pada bentuk fasad dan bukaan, bentuk fasad di sesuaikan dengan iklim yang ada dengan kemiringan atap yang cocok pada iklim tropis sehingga dalam menghalau air hujan lebih baik, dalam bukaan juga sangat penting karena berpengaruh dalam penggunaan pendingin ruangan dan lampu. Penggunaan material lokal yaitu dengan material kayu karena material kayu dapat di peroleh dari sekitar site sehingga sangat berperan penting dalam menciptakan kawasan yang ekologi. Dalam meminimalkan dampak negatif pada alam dengan di lakukan pengolahan limbah sampah organik maupun anorganik dengan cara di bakar untuk jadi bahan kompos atau di kumpulkan untuk di angkut ke tempatnya. Dalam dalam penyerapan gas buang dalam studi kasus melakukan dengan tumbuhnya pohon-pohon agar pohon tersebut bisa mengolah udara yang tidak baik menjadi udara baik atau segar. Dalam Menggunakan teknologi yang mempertimbangkan nilai nilai ekologi dari elektronik itu sendiri bisa menggunakan pendingin ruangan yang sudah berstandar eco, dan penerangan menggunakan lampu led karena lampu jenis ini lebih hemat daya listriknya, dalam bangunan bisa dengan menggunakan bahan baku kayu yang sesui dengan lokasi sehingga bangunan yang berdiri tetap menyatu dengan alam sehingga tidak merusak ekosistem yang ada.

\section{DAFTAR PUSTAKA}

A. R. Adi, Kajian Konsep Ekologis Pada Gedung Perpustakaan Pusat UGM. ATRIUM, Vol. 3, No. 1, 2017.

P. M. Ahli, Pengertian Resort. Retrieved from www.pengertianmenurutparaahli.net, Maret 2015 (Online), . Tersedia https://www.pengertianmenurutparaahli.net Lpengertian-resort/ (Diakses 18 Oktober 2019)

F. Ching, Arsitektur Bentuk Ruang dan Tatanan. Jakarta: Penerbit Erlangga, 2008.

H Frick, \& Bambang, S. Dasar dasar arsitektur ekologis. Semarang: PT Kanisius, 2007.

L. Hakim, \& Budi, N. Penerapan Arsitektur ekologis pada desain rumah tinggal., 2017, Nalars, 3148.

S. Mahardika, \& Widji, I. T. Penerapan Arsitektur Ekologis pada Perancangan Sekolah Tinggi Seni Pertunju kandi Kabupaten Bandung Barat. Jurnal Online Institut Teknologi Nasional, Vol.1 No. 3; tahun 2013.

A. A. Muslim,, Ashadi, \& Anggana, F. S, Konsep Arsitektur Ekologi Pada Penataan Kawasan Wisata Candi Cangkuang Di Garut Jawa Barat. Purwarupa, , pp 57-70, tahun 2018.

S. R Pratama, Maya, A. N., \& Samsudi, Penerapan Arsitektur Ekologis Pada Perancangan Pesantren Agrobisnis Di Karanganyar. Jurnal SENTHONG, Vol. 1, No.2, pp 171-178.

Ramadhan. (2013). Kawasan Hotel Resort dan Homestay di Pulau Lemukutan Kabupaten. Jurnal online mahasiswa Arsitektur "Langkau Betang", pp 13-27, tahun 2018.

M. Sakti,, Wiwik, S., \& Made, S. Penerapan Prinsip Arsitektur Ekologis Pada Pembangunan Agrowisata Teh Kemuning Di Karang Anyar. Jurnal Senthong, pp 163-172, tahun 2019.

Sidik, \& Daniel, F, Implementasi Konsep Arsitektur Ekologi Pada Rancang Bangun Rumah Minimalis. Techno Nusa Mandiri,pp 23-31, . 2016.

E, Y. Titisari, Joko T, S., \& Noviani, S. Konsep Ekologis pada Arsitektur di Desa Bendosari. Jurnal Ruas, pp 20-31, tahun 2012.

W. I. Tyas, Fairuz, N., Annisa, P., \& Suci, I. S, . Orientasi Bangunan Terhadap Kenyamanan Termal pada Rumah Susun Leuwigajah Cimahi. Jurnal 
Online Institut Teknologi Nasional, No 1. Vol 3, tahun 2015.

A. D. Utami, Sri, Y., \& Ummul, M. Penerapan Arsitektur Ekologis Pada Strategi Perancangan Sekolah Menengah Kejuruan Pertanian Di Sleman. Arsitektura, 341. Tahun 2017. 